\title{
Identification and quantification of additives in bituminous binders based on FTIR spectroscopy and multivariate analysis methods
}

\author{
Sandra Weigel $\mathbb{D} \cdot$ Michael Gehrke $\cdot$ Christoph Recknagel $\cdot$ Dietmar A. Stephan $\mathbb{C}$
}

Received: 11 May 2021/Accepted: 27 July 2021 / Published online: 6 August 2021

(C) The Author(s) 2021

\begin{abstract}
Bitumen is a crucial building material in road construction, which is exposed to continuously higher stresses due to higher traffic loads and changing climatic conditions. Therefore, various additives are increasingly being added to the bitumen complicating the characterisation of the bituminous binder, especially concerning the reuse of reclaimed asphalt. Therefore, this work aimed to demonstrate that the combination of Fourier transform infrared (FTIR) spectroscopy with attenuated total reflexion (ATR) technique and multivariate evaluation is a very wellsuited method to reliable identify and quantify additives in bituminous binders. For this purpose, various unmodified and modified binders, directly and extracted from laboratory and reclaimed asphalts, were investigated with FTIR-ATR spectroscopy. The determined spectra, pre-processed by standard normal variate (SNV) transformation and the determination of the 1st derivation, were evaluated using factor analysis (FA), linear discriminant analysis (LDA) and partial least square regression (PLSR). With this multivariate evaluation, first, a significant model with a very high
\end{abstract}

S. Weigel $(\bowtie) \cdot C$. Recknagel · D. A. Stephan Federal Institute for Materials Research and Testing (BAM), Unter den Eichen 87, 12205 Berlin, Germany e-mail: sandra.weigel@bam.de

\section{Gehrke}

Ingenieurgesellschaft für Technische Analytik mbH (IFTA GmbH), Lüschershofstraße 71-73, 45356 Essen, Germany hit rate of over $90 \%$ was developed allowing for the identification of styrene-butadiene copolymers (SBC), ethylene-copolymer bitumen (ECB) and different waxes (e.g. amide and Fischer-Tropsch wax) even if the additives do not show any additional peaks or the samples are multi-modified. Second, a quantification of the content is possible for $\mathrm{SBC}, \mathrm{ECB}$, and amide wax with a mean error of RMSE $\leq 0.4$ wt $\%$ and a coefficient of determination of $R^{2}>90 \%$. Based on these results, FTIR identification and quantification of additives in bituminous binders is a very promising method with a great potential.

Keywords Bituminous binders · FTIR-ATR . Multivariate evaluation - Identification and quantification of additives · Polymers · Waxes

\section{Introduction}

As a crucial element of our infrastructure, roads are essential for the modern economy and society. In Europe, over $90 \%$ of the roads are made of asphalt with bituminous binders [1]. Asphalt is principally very suitable for reuse due to the thermoplastic properties. Thus, reclaimed asphalt is reused at very high rates, e.g. approx. $82 \%$ in Germany, approx. 94\% in the United States of America and even $100 \%$ in Finland (status 2019) [2]. For reuse, the asphalt must 
meet different criteria, which refer in particular to the binder. In Germany, the essential criterion is the softening point ring and ball $\left(T_{\mathrm{R} \& \mathrm{~B}}\right)$, which may assume a maximum of $70{ }^{\circ} \mathrm{C}$ to limit the ageing state of the binder [3]. This criterion was initially developed for unmodified bitumen. Nowadays, however, bitumen is increasingly modified with additives to improve the asphalt properties, save resources, or protect the environment and health. These modified binders often have relatively high softening points caused by the additives and not by an advanced ageing. Therefore, it is essential to identify the additives allowing for a differentiated interpretation of $T_{\mathrm{R} \& \mathrm{~B}}$ and the state of the binder. However, such an identification of the additives is not yet easily possible. There are several approaches for additive identification in bituminous binders, for example with the dynamic shear rheometer (DSR) [4-8] or the differential scanning calorimetry (DSC) [9-11], but the possibilities of these methods are very limited, especially concerning the additive types. An innovative method for identifying additives in bituminous binders is the Fourier transform infrared (FTIR) spectroscopy enabling the detection of chemical compounds and molecular building blocks in a sample. It is already known that the FTIR spectroscopy allows for the recognition of polymers like styrene-butadiene type copolymers (SBC) or waxes like synthetic hard waxes due to the additional peaks in the spectra [12-16]. Based on this knowledge, in this work, the question was investigated whether the FTIR spectroscopy can also be used to identify further additives including additives that cause no additional peaks in the FTIR spectra and thus are not visually detectable. To capture these additives nevertheless, a multivariate approach was applied. This approach has the advantages that even minor differences of the FTIR spectra can be recognized and captured as well as multiple variables can be considered and evaluated simultaneously and thus a holistic view of the binder spectra will be possible. Further, it was investigated whether a prognosis of the additive content can be made based on the FTIR spectra and the multivariate evaluation. In general, different studies could show that, with these methods, various information about the structure and properties of bituminous binders and other petroleumbased products could be gained [17-20].

\section{Materials and methods}

\subsection{Materials}

The basis of the presented work is formed by various unmodified and modified bituminous binders, asphalts produced from them and reclaimed asphalts. Concerning the binders, most of the samples were selfproduced so that the types and the contents of the additives were explicitly known. Thereby, four different paving grade bitumen according to EN 12591 [21] from two different refineries ( $A$ and $B$ ) designated 20/30 A, 50/70 A, 70/100 A and 70/100 B were modified with various additives commonly used in Germany including styrene-butadiene copolymers (SBC) and ethylene-copolymer bitumen (ECB) as polymers as well as amide wax (amide), FischerTropsch wax (FT wax) and montan wax A and B (Mo A, Mo B) as waxes. The modification procedures are summarised in Table 1, whereby the additive amount was varied between 1 and $5 \mathrm{wt} \%$. Individual samples were also modified several times, combining both the two polymers (SBC and ECB) as well as a polymer (SBC or ECB) and a wax (amide or FT wax).

In addition to the self-modified binders, binders being already modified from the manufacturer were obtained, including especially the polymer-modified binders 25/55-55 A according to EN 12591 [21] from the two refineries A and B and 40/100-65 A according to EN 12591 [21] from refinery A. For these manufacturer-modified binders, no information was available regarding the types and contents of the polymer or potential additional additives.

Both the self-modified and the manufacturer-modified binders were principally investigated in the unaged state. In addition, to consider ageing effects on the additive identification, several samples were also artificially aged using the Rolling Thin Film Oven Test (RTFOT at $163{ }^{\circ} \mathrm{C}$ for $75 \mathrm{~min}$ according to EN 12607-1 [22]) and the ageing simulation with Pressure Ageing Vessel (PAV at $100{ }^{\circ} \mathrm{C}$ and 2.1 MPa for $20 \mathrm{~h}$ according to EN 14769 [23]).

Further, asphalt samples were produced from selected binder samples to evaluate influences from asphalt production and binder extraction on the additive identification. For this purpose, a unified asphalt concrete with a maximum grain size of $8 \mathrm{~mm}$ (AC $8 \mathrm{DN}$ according to the German standard TL Asphalt-StB 07/13 [3]) was selected using a uniform 
Table 1 Overview of modification procedures

\begin{tabular}{|c|c|c|}
\hline Additive & $\begin{array}{l}\text { Mixing } \\
\text { temperature }\left({ }^{\circ} \mathrm{C}\right)\end{array}$ & Mixing procedure \\
\hline SBC & 190 & $\begin{array}{l}30 \mathrm{~min} \text { with high shear mixer (approx. } 8500 \mathrm{rpm} \text { ), then addition of } 0.03 \mathrm{wt} \% \text { sulphur per } 1 \mathrm{wt} \% \\
\text { SBC as cross-linking agent and mixing further } 30 \mathrm{~min} \text {, then mixing } 3 \mathrm{~h} \text { with paddle stirrer } \\
\text { (approx. } 100 \mathrm{rpm} \text { ) }\end{array}$ \\
\hline ECB & 170 & 60 min with paddle stirrer (approx. $100 \mathrm{rpm}$ ) \\
\hline Waxes & 160 & 30 min with paddle stirrer (approx. $100 \mathrm{rpm}$ ) \\
\hline
\end{tabular}

coarse and fine aggregate of diabase and a uniform limestone filler. To several asphalt samples, cellulose fibres, being used e.g. in stone mastic asphalt (SMA) and open-pored asphalt (OPA) or higher filler contents being used e.g. in mastic asphalt (MA), were also added to consider their influence on the detectability of the additives. The asphalt samples were also aged by storing at $80{ }^{\circ} \mathrm{C}$ for $96 \mathrm{~h}$ according to CEN/TS 12697-52 [24].

In addition to the targeted produced asphalt samples, reclaimed asphalts without and with polymer-, wax- and multi-modifications were also investigated to consider different asphalt mixtures, the paving and recovery procedures, as well as natural ageing processes. The service life of these reclaimed asphalts varied from a minimum of 5 years to over 18 years.

Concerning both the self-produced and the reclaimed asphalts, the binders were extracted carrying out 8 washes with trichloroethene in a closed extraction plant and a following distillation (according to EN 12697-1 [25]).

In total, 79 samples were obtained including 45 samples directly of the unmodified, self-, and manufacturer-modified binders, 20 samples extracted from laboratory asphalts and 14 samples extracted from reclaimed asphalts. All these sample groups, the direct binder samples as well as the samples from the laboratory and reclaimed asphalts, included unmodified, polymer-, wax- and multi-modified binders. Thereby, 68 samples were modified with one additive and 11 samples were multi-modified with two additives.

Among the samples, also a few rubber-modified samples were present. However, due to the small number of samples and different rubber modifications, no significant statement about the potential identification was possible. Therefore, this modification group was not considered further.

\subsection{Methods}

\subsubsection{Fourier transform infrared (FTIR) spectroscopy}

All the 79 samples were investigated with FTIR spectroscopy using the instrument Perkin Elmer Spectrum Two FT-IR C96108 with Attenuated Total Reflection (ATR) technique in the form of a diamond with a single reflection. For every sample, seven single measurements without further sample preparation were carried out considering 32 scans, a wave number range from 4000 to $600 \mathrm{~cm}^{-1}$ and a resolution of $4 \mathrm{~cm}^{-1}$. Due to the high number of single measurements, the scatter of the measurement could be taken into account in the evaluation and thus in developing the identification and quantification models.

The obtained reflectance spectra were converted in absorbance spectra and only the relevant wave number ranges between 3700 and $2500 \mathrm{~cm}^{-1}$ and 1800 and $600 \mathrm{~cm}^{-1}$ including the peaks of the spectra were considered. In addition, an interference peak was detected in the range between 940 and $919 \mathrm{~cm}^{-1}$ which is caused by solvent residues from the extraction. Due to the falsified information of this peak, the affected wave number range was also eliminated from the spectra. To eliminate further disturbance effects, the three spectra ranges from 3700 to $2500 \mathrm{~cm}^{-1}$, 1800 to $940 \mathrm{~cm}^{-1}$ and 919 to $600 \mathrm{~cm}^{-1}$ were preprocessed with the standard normal variate (SNV) transformation and the determination of the 1st derivative (according to Kessler [23]). The data preprocessing was done with the software The Unscrambler X $10.3^{\odot}$. 


\subsubsection{Statistical methods}

To develop a model for identifying the additives based on the FTIR spectra, multivariate analysis methods in form of the factor analysis (FA) and the linear discriminant analysis (LDA) were used. The FA enables a data reduction [26] so that the spectra could be described by a small number of 7 superordinate factors instead of over 2000 wave numbers. The LDA allows a mathematical description of different groups and the classification of unknown samples into the described groups [26]. By combining FA and LDA application, a model can be developed that can be used to systematically examine whether an unknown sample belongs to one of the defined groups [18]. In the present case, the defined groups are the various modification and thus additive groups, so that the additives SBC, ECB, amide, FT wax, Mo A and Mo B form all individual groups. For more detailed information about the FA and LDA, the exact procedure of the method combination, and the boundary conditions of the analyses, please refer [18], in which the same approach was used for a different question.

The result of the combined FA and LDA evaluation is a multi-level decision tree. At each level of this decision tree, the modification group with the most significant spectral differences is separated from the other binder groups. Thereby, the spectral differences between the groups decrease continuously from the first to the last level [18].

For the development and validation of the identification models, in a first step, solely the singlemodified samples were considered and the data set of the 68 single-modified samples was divided into a calibration and a validation data set. The calibration data set included 45 samples and the validation data set 23 samples, both containing laboratory binder and asphalt samples as well as samples from reclaimed asphalts. In this way, the influence of paving, recovery, and extraction procedures as well as natural ageing processes was already considered during the model development. To separate the calibration and validation data set, the FA was used as described in [27]. In a second step, the multi-modified binders were also considered. But due to the small number of only 11 samples, this data set could not be divided into calibration and validation data sets.

To derive the additive content from the FTIR spectra, the partial least square regression (PLSR) was used, allowing for the description of functional relationships between a dependent variable and various independent variables. The specific advantage of the PLSR is that it also includes a factor analysis and, thus, highly correlated variables can be used as $x$ variables. Due to the comparatively small number of samples (18-19 samples) within the considered modification groups (SBC, ECB, amide, FT wax), instead of a division into calibration and validation set, a cross-validation under exclusion of one sample in each case was carried out [26].

In general, the FA and the LDA were carried out with the software IBM SPSS Statistics $24^{\odot}$, while the software The Unscrambler X $10.3^{\odot}$ was used for the PLSR method.

\section{Results and discussion}

\subsection{FTIR spectra of modified bitumen binders}

The pre-processed FTIR spectra show that most of the investigated additives have characteristic bands differing from the typical bitumen bands. However, for some additives, the bands overlap entirely with those of the bitumen. To demonstrate this, Fig. 1 presents the SNV standardised mean spectra of the unmodified bitumen 70/100 A and the polymer-modified samples 70/100 A with $5 \mathrm{wt} \%$ SBC and 70/100 A with $5 \mathrm{wt} \%$ ECB. At this point, the completely pre-processed spectra are not shown, because the spectral form and thus the clearness of the spectra is lost through the calculation of the 1 st derivative.

In Fig. 1, the most important typical bitumen bands are marked and assigned to the corresponding chemical compounds or molecule building blocks. Furthermore, Fig. 1 shows the additional bands of the polymer-modified binders that appear at approx. $965 \mathrm{~cm}^{-1}, 911 \mathrm{~cm}^{-1}$ and $695 \mathrm{~cm}^{-1}$ for SBC and at approx. $1730 \mathrm{~cm}^{-1}$ for ECB. The bands of SBCmodified binders are relatively well known, allowing the assignment of the band at $965 \mathrm{~cm}^{-1}$ to $1,4-$ butadiene, the band at $911 \mathrm{~cm}^{-1}$ to 1,2-butadiene and the band at $695 \mathrm{~cm}^{-1}$ to styrene [16]. The comparatively small characteristic band of the ECB-modified binders is only formed when ECB and bitumen are mixed and is probably caused by alkene compounds (according to [28]). 


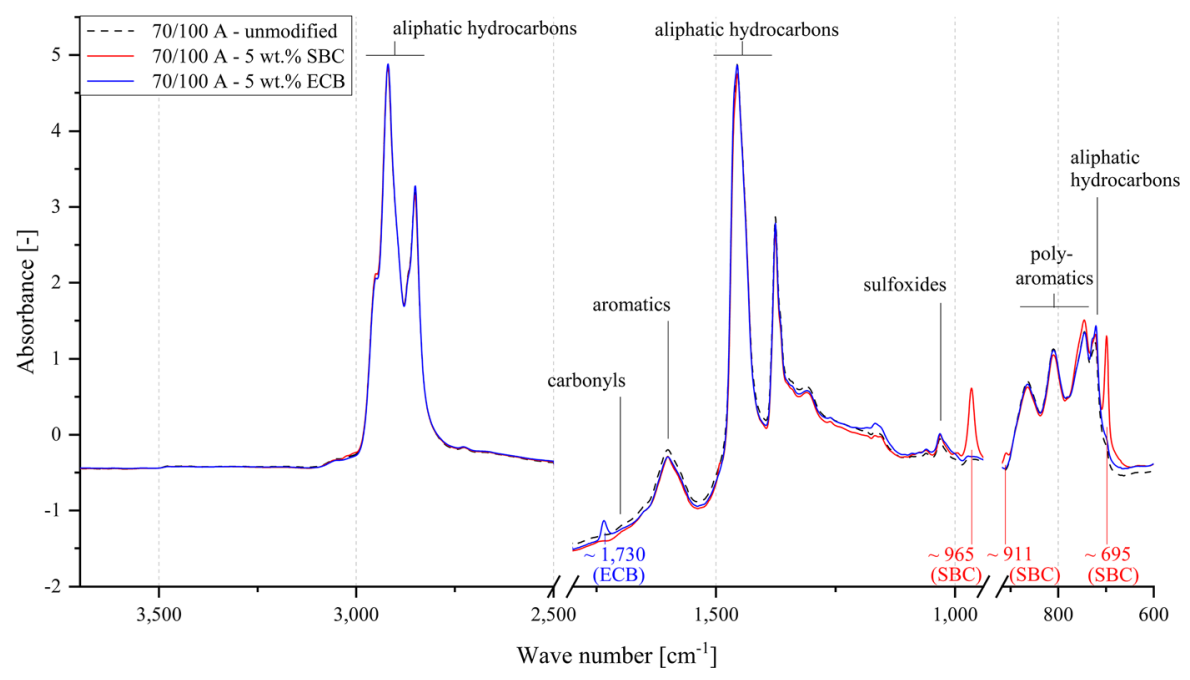

Fig. 1 SNV standardised mean spectra of the bitumen 70/100 A in the unmodified state and modified with 5 wt $\%$ SBC and 5 wt $\%$ ECB (Peak labelling according to Mouillet et al. [15], van den Bergh [29] and Feng et al. [30])

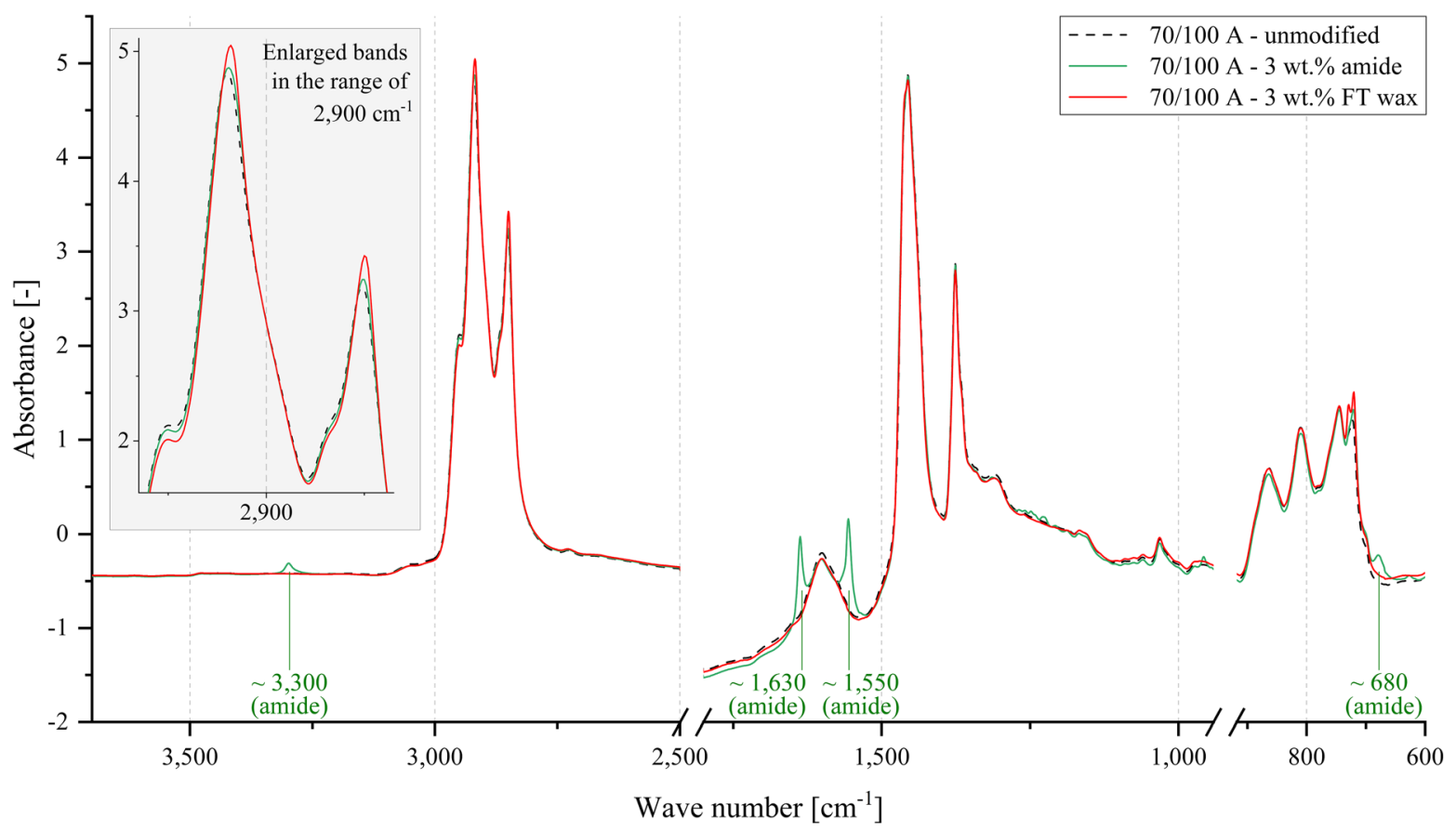

Fig. 2 SNV standardised mean spectra of the bitumen 70/100 A in the unmodified state and modified with 3 wt $\%$ amide and 3 wt $\%$ FT wax

Figure 2 shows the unmodified bitumen 70/100 A and different wax-modified binders based on this bitumen, including the samples with $3 \mathrm{wt} \%$ amide and $3 \mathrm{wt} \%$ FT wax. The modifications with the montan waxes are not separately shown, because the montan waxes causes comparable structural changes as the amide or the FT wax. In Germany, the amide and the Mo A are classified as $\mathrm{VH}$ waxes with viscositychanging properties due to a high transition temperature $\left(\geq 100^{\circ} \mathrm{C}\right)$, while the FT wax and Mo B belong to the VL waxes with viscosity-changing properties due to a low transition temperature $\left(<100{ }^{\circ} \mathrm{C}\right)$ [31]. 
According to Fig. 2, the amide wax cause characteristic bands at approx. $3300 \mathrm{~cm}^{-1}, 1630 \mathrm{~cm}^{-1}$, $1550 \mathrm{~cm}^{-1}$ and $680 \mathrm{~cm}^{-1}$, which are most likely caused by the amide compounds in this wax group (according to [28]). Comparable results were obtained for the binders with Mo A. So, the investigated representatives of the group of the $\mathrm{VH}$ waxes can be clearly identified by these bands.

In contrast, the FT wax and also the Mo B do not lead to any characteristic bands in the binder spectra illustrated in Fig. 2 for a FT wax-modified binder. Thus, the investigated representatives of the VL wax group cannot be identified by visual evaluation of the FTIR spectra. However, since the addition of these additives results in changes in the physical properties and, in turn, the physical properties are fundamentally dependent on the structure of the material, the addition of the additives must also cause structural changes and, therefore, changes in the FTIR spectra. These can occur, e.g. in the form of slight differences in individual band intensities demonstrated for the bands in the range of $2900 \mathrm{~cm}^{-1}$ in the enlargement of Fig. 2. However, these differences can only be captured in detail by multivariate evaluations being thus urgently needed to identify these additives.

\subsection{Multivariate evaluation-identification of the additives}

To identify additives without additional characteristic bands and to automatise the additive identification, the multivariate evaluation with combined application of FA and LDA was carried out. At first, only the singlemodified samples and thus the calibration data set of

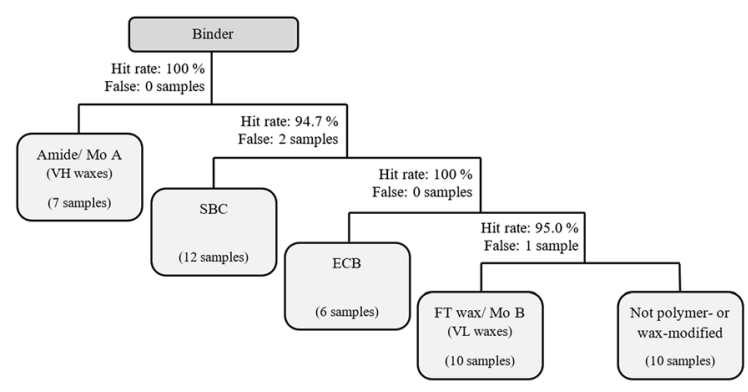

Fig. 3 Binary decision tree for the separation of singlemodified additives in bituminous binders with indication of the number of samples per group, hit rate, and number of incorrectly grouped samples
45 samples were considered resulting in the binary decision tree pictured in Fig. 3.

This decision tree shows different levels, each of which separates an additive or modifier group from the other binders. In Fig. 3, the number of samples per group, the hit rate achieved, and the number of incorrectly grouped samples are also indicated. In principle, a sample was considered to be correctly classified if at least 5 out of 7 individual measurements were assigned to the correct additive group.

This decision tree confirms the previous findings obtained from the visual observation of the spectra. According to Sect. 3.1, the groups with the most significant differences to the other samples are distinguished on the individual levels. Thus, on the first level, the $\mathrm{VH}$ waxes with four additional bands, on the second level, the SBC polymer with three additional bands, on the third level, the ECB polymer with one additional band and, on the last level, the VL waxes without additional bands were separated. Figure 3 further demonstrates that high to very high hit rates of 90 to $100 \%$ were achieved at the individual levels indicating a high model quality. Thus, the differences between the spectra of the samples can be detected very well with this model, also including the differences between the VL wax-modified and the unmodified samples. Only a few samples, e.g. with a very low additive concentration of only $1 \mathrm{wt} \%$, were not correctly assigned.

Further evaluation of the developed model was carried out through statistical variables including Wilks' Lambda $\Lambda$ as well as $\chi^{2}$ approx and thus the associated significance level. These statistical parameters also confirm the high quality of the model demonstrating that the probability of error for the presence of two different groups at each level was $0 \%$. Applying the model to the validation data set also emphasises the high model accuracy because $100 \%$ of the 23 validation samples were grouped correctly.

In a further step, the identification possibility for multi-modified binder samples was investigated. In this context, it should be noted that only a very small sample size was available for these investigations and thus the results should be regarded as first trials. These first trials showed that by extending the existing decision tree in Fig. 3, it is also possible to identify multiple modifications. The existing decision tree first identifies the dominant additive and classifies the sample appropriately. Due to the extension of the 
decision tree, it is then verified in each group whether other additives are present in the considered sample. Figure 4 show this extension as an example for the group of the SBC-modified samples.

According to this figure, high accuracy was also achieved for this extension of the decision tree. In addition to the SBC group, this high accuracy also applies to the other investigated additive groups, including the ECB polymer as well as the $\mathrm{VH}$ and $\mathrm{VL}$ waxes. Consequently, identification of multiple modifications is also possible based on the FTIR spectra and the multivariate evaluation. However, the order of the distinguished additive groups is conspicuous, because after the group "SBC + amide", the group "SBC + FT-wax" and then the group "SBC + ECB" are separated. A possible explanation for this could be structural changes caused by interactions during the modification with different additives. However, regarding these decision tree extensions, the small number of samples should be mentioned again requiring the verification of the results.

\subsection{Multivariate evaluation-quantification of the additives}

In addition to identify different additives in bituminous binders, a further approach investigated whether quantification of the additives is also possible. Therefore, models were developed with the PLSR describing the additive content (dependent variable) by the SNV-standardised and derived spectral data of the relevant wave number ranges (independent variables). In this context, it remains to be noted that the number

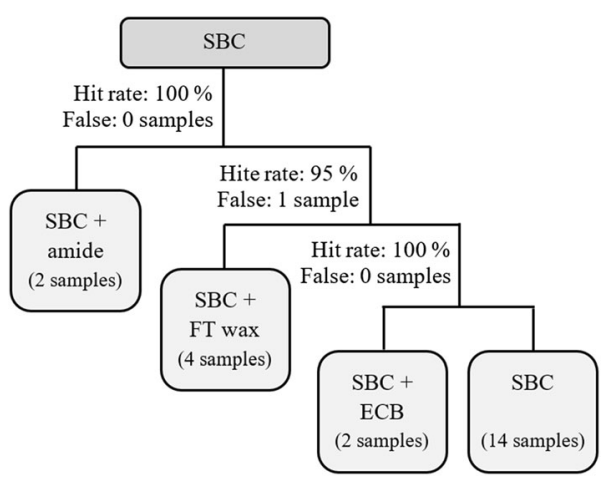

Fig. 4 Extended decision tree of Fig. 3 for the identification of multiple modifications using the sample of the SBC additive group of samples for these investigations was comparatively small. Therefore, the results should also be considered as first trials and verified by a more extensive data set. Nevertheless, according to these analyses, the FTIR spectra allow to estimate the content of almost all investigated additives. Figure 5 demonstrates this possible estimation for the SBC polymer by comparing the true and the calculated contents.

Based on the mean error RMSE and the coefficient of determination $R^{2}$, the model allows for a very good prediction of the SBC content. However, it could be seen that the deviations increase noticeably at the higher concentrations, especially at $5 \mathrm{wt} \%$. This observation should be verified by further investigations with a more extensive data set including a larger number of samples with higher SBC contents. Nevertheless, the major advantage of this approach is that all spectra bands and thus all SBC bands are considered for the quantification. This also allows the model to estimate the content of SBC products with different compositions.

For the additives ECB and amide, a slightly lower validation accuracy of the prediction models was found with mean error of $\mathrm{RMSE}=0.4 \mathrm{wt} \%$ and coefficient of determination of $R^{2}=97 \%$ for ECB and RMSE $=0.35 \mathrm{wt} \%$ and $R^{2}=93 \%$ for amide. For these two models, the occurring deviations are particularly evident for the unmodified and the most highly modified samples. Even though the prediction models should be verified with a more extensive data set, these results show that an estimation of the content of SBC, ECB and amide is principally possible.

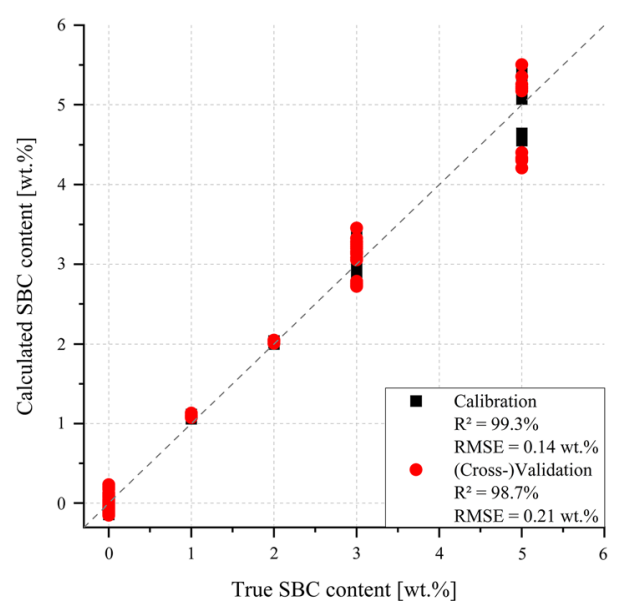

Fig. 5 Comparison of the true and calculated contents of the SBC polymer 
In contrast, for the FT wax, it was not possible to generate a satisfactory prediction model for estimating the additive content. This is most likely caused by the missing characteristic bands requiring a very large calibration data set.

\section{Conclusion}

This work shows that FTIR spectroscopy combined with multivariate evaluation is a very useful method to identify and quantify additives in bituminous binders. For this, various binders were investigated including unmodified, self-modified and manufacturer-modified binders as well as extracted binders from laboratory and reclaimed asphalts. Concerning the additive, polymers in the form of styrene-butadiene copolymers (SBC) and ethylene copolymer bitumen (ECB) as well as waxes in the form of amide wax (amide), FischerTropsch wax (FT wax) and two montan waxes (Mo A and B) were considered. The FTIR spectra of the modified binders show additional characteristic bands besides the bitumen ones for the additives SBC, ECB, amide, and Mo A. In contrast, for the FT wax and Mo $\mathrm{B}$, the bitumen and additive bands overlap completely.

To obtain comprehensive information about the modification of the spectra, nevertheless, and to automatise the spectra evaluation, identification and quantification models were developed using multivariate analysis methods. For this, the spectra were first pre-processed by the standard normal variate (SNV) transformation and the determination of the 1st derivative. To develop the identification model, a combined evaluation with factor analysis (FA) and linear discriminant analysis (LDA) was carried out, while the partial least square regression (PLSR) was used to develop the quantification models.

Based on the identification model, reliable identification of various additives was achieved, whereby the hit rate of over $90 \%$ demonstrates the high quality of this model. The detectable additives include SBC, ECB, VH waxes (amide and Mo A) and VL waxes (FT wax and Mo B) and thus also additives without additional characteristic bands. Furthermore, various multiple modifications from the abovementioned additives can also be identified.

Additionally, an estimation of the content of SBC, ECB and amide wax is possible with different quantification models. Thereby, with a mean error
RMSE $\leq 0.4 \mathrm{wt} \%$ and a coefficient of determination $R^{2}>90 \%$, high accuracy of these models was achieved. However, for the FT wax without additional characteristic bands, no satisfactory estimation model for the content could be obtained with the available data. To develop a reliable model for this, a very high number of calibration samples is probably required.

According to the results of this work, FTIR spectroscopy with combined multivariate evaluation is a very well-suited method to identify and also quantify additives in bituminous binders. Thus, this tool allows to determine the composition of bituminous products, which can be used, e.g., for quality control, but especially for the characterisation of reclaimed asphalts. Due to the simple measurement procedure and fast automated evaluation, FTIR identification and quantification are ideal for practical use.

As an outlook, verification with a larger data set and an extension of the models with additional additives should be carried out in further research. Moreover, the comparability between the measurements of different laboratories and the general validity of the identification and quantification models should be considered and optimised if necessary.

Funding Open Access funding enabled and organized by Projekt DEAL. This report is based on parts of a research project carried out at the request of German Federal Ministry of Transport and Digital Infrastructure, represented by the German Federal Highway Research Institute, under research project No. $07.0286 / 2016 / \mathrm{EGB}$. The authors are solely responsible for the content.

\section{Declaration}

Conflict of interest The authors declare that they have no conflict of interest.

Open Access This article is licensed under a Creative Commons Attribution 4.0 International License, which permits use, sharing, adaptation, distribution and reproduction in any medium or format, as long as you give appropriate credit to the original author(s) and the source, provide a link to the Creative Commons licence, and indicate if changes were made. The images or other third party material in this article are included in the article's Creative Commons licence, unless indicated otherwise in a credit line to the material. If material is not included in the article's Creative Commons licence and your intended use is not permitted by statutory regulation or exceeds the permitted use, you will need to obtain permission directly from the copyright holder. To view a copy of this licence, visit http://creativecommons.org/licenses/by/4.0/. 


\section{References}

1. EAPA, Homepage. https://eapa.org/asphalt/. Accessed 28 Jan 2021

2. European Asphalt Pavement Association (EAPA, 2019) Asphalt in Figures 2019. https://eapa.org/wp-content/ uploads/2020/12/Asphalt-in-figures_2019.pdf. Accessed 28 Jan 2021

3. Road and Transportation Research Association (FGSV) (2013) Technical delivery conditions for asphalt mixture in pavement construction (TL Asphalt-StB 07/13). FGSV, Cologne

4. Gehrke M (2017) Complex characterisation of bituminous binders based on temperature-, frequency- and load-dependent parameters. Dissertation, Ruhr-Universität Bochum

5. Alisov A (2017) Typification of bitumen using transient oscillation rheometry. Dissertation, Technische Universität Braunschweig

6. Polacco G, Filippi S, Paci M, Giuliani F, Merusi F (2012) Structural and rheological characterization of wax modified bitumens. Fuel 95:407-416. https://doi.org/10.1016/j.fuel. 2011.10.006

7. Whiteoak D, Read J (2003) The shell bitumen handbook. Thomas Telford Publishing, London

8. Gogolin D (2012) Rheological parameters of bituminous binders for the characterisation of acoustic properties of asphalt wearing course. Dissertation, Ruhr-Universität Bochum

9. Masson JF, Polomark G (2001) Bitumen microstructure by modulated differential scanning calorimetry. Thermochim Acta 374(2):105-114. https://doi.org/10.1016/S00406031(01)00478-6

10. Masson JF, Polomark G, Collins P (2005) Glass transition and amorphous phases in SBC-bitumen blends. Thermochim Acta 436:96-100. https://doi.org/10.1016/j.tca. 2005.02.017

11. Merussi F, Filippi S, Polacco G (2017) Effect of synthetic and functionalized waxes on bituminous binders: from glassy state of the intermediate viscoelastic domain. Constr Build Mater 136:541-555. https://doi.org/10.1016/j. conbuildmat.2017.01.062

12. Masson JF, Pelletier P, Collins P (2001) Rapid FTIR method for quantification of styrene-butadiene type copolymers in bitumen. J Appl Polym Sci 79:1034-1041. https://doi.org/ 10.1002/1097-4628(20010207)79:6\%3c1034::AIDAPP60\%3e3.0.CO;2-4

13. Tang JQ, Ma QF, Shi JT, Yuan H, Song CF, Xie JC, Li XY (2016) Rapid FTIR-ATR method for the quantification of bitumen properties. Guang $\mathrm{Pu}$ Xue Yu Guang Pu Fen Xi 36:627-675

14. Wu S, Pang L, Liu G, Zhu J (2010) Laboratory study on ultraviolet radiation aging of bitumen. J Mater Civ Eng 22:767-772. https://doi.org/10.1061/(ASCE)MT.19435533.0000010

15. Mouillet V, Farcas F, Besson S (2008) Ageing by UV radiation of an elastomer modified bitumen. Fuel 87:2408-2419. https://doi.org/10.1016/j.fuel.2008.02.008

16. Beer F, Krotmann E, Friemel-Göttlich B, Peters A (2000) Chemical and physical characterisation of norm and polymer modified bitumen, Part 1: Development and application of methods for chemical charactersiation of norm and polymer modified bitumen. Federal Highway Research Institute, Bergisch Gladbach

17. Weigel S, Stephan D (2018) Bitumen characterization with Fourier transform infrared spectroscopy and multivariate evaluation: prediction of various physical and chemical parameters. Energy Fuel 32:10437-10442. https://doi.org/ 10.1021/acs.energyfuels.8b02096

18. Weigel S, Stephan D (2018) Differentiation of bitumen according to the refinery and ageing state based on FTIR spectroscopy and multivariate analysis methods. Mater Struct 51(130):1-11. https://doi.org/10.1617/s11527-0181252-6

19. de Peinder P (2009) Characterization and classification of crude oils using a combination of spectroscopy and chemometrics. Dissertation, Universiteit Utrecht

20. Thimm L (2009) FTIR and FTNIR spectroscopy investigations combined with chemometric analysis algorithms for the characterisation of the chemical composition of bitumen. Dissertation, Universität Duisburg-Essen

21. European Committee for Standardization (CEN)-EN 12591 (2009) Bitumen and bituminous binders-specification of paving grade bitumens. CEN, Brussels

22. European Committee for Standardization (CEN)-EN 12607 (2013) Bitumen and bituminous binders-determination of the resistance to hardening under the influence of heat and air-part 1: RTFOT method. CEN, Brussels

23. European Committee for Standardization (CEN)-EN 14769 (2012) Bitumen and bituminous binders-accelerated long-term ageing conditioning by a pressure ageing vessel (PAV). CEN, Brussels

24. European Committee for Standardization (CEN) - CEN/TS 12697 (2017) Bituminous mixtures-test methods-part 52: Conditioning to address oxidative ageing. CEN, Brussels

25. European Committee for Standardization (CEN)-EN 12697 (2012) Bituminous mixtures-test methods for hot mix asphalt-part 1: soluble binder content. CEN, Brussels

26. Kessler W (2007) Multivariate data analysis. Wiley-VCH Verlag, Weinheim

27. Weigel S, Stephan D (2017) The prediction of bitumen properties based on FTIR and multivariate analysis methods. Fuel 208:655-661. https://doi.org/10.1016/j.fuel.2017. 07.048

28. Gottwald W, Wachter G (1997) IR spectroscopy for users. Wiley-VCH Verlag, Weinheim

29. van den Bergh W (2011) The effect of ageing on the fatigue and healing properties of bituminous mortars. Dissertation, Technische Universiteit Delft

30. Feng Z, Bian H, Li X, Yu J (2016) FTIR analysis of UV aging bitumen and its fractions. Mater Struct 49:1381-1389. https://doi.org/10.1617/s11527-015-0583-9

31. German Road and Transportation Research Association (FGSV)—E KvB (2016) Recommendations for the classification of viscosity-changed binders. FGSV, Cologne

Publisher's Note Springer Nature remains neutral with regard to jurisdictional claims in published maps and institutional affiliations. 